\title{
PERENCANAAN PONDASI TIANG (Studi Kasus HOTEL MERDEKA TULUNGAGUNG)
}

\author{
Rohmat Ilyas Kurniawan *1, Ahmad Ridwan ${ }^{2}$, Sigit Winarto ${ }^{3}$, Agata Iwan Candra ${ }^{4}$. \\ ${ }^{1,2,3}$ Fakultas Teknik, Universitas Kadiri. \\ e-mail: ${ }^{* 1}$ rohmat_ilyas@gmail.com, ${ }^{2}$ ahmad_ridwan@unik-kediri.ac.id, \\ ${ }^{3}$ sigit.winarto@unik-kediri.ac.id, ${ }^{4}$ iwan candra@unik-kediri.ac.id.
}

\begin{abstract}
The foundation is a construction at the base of the building, which functions to transmit the load from the top of the building structure to the soil layer at the bottom. The pile type foundation is a foundation that is often planned in such conditions. Therefore it is necessary to calculate incorrectly in foundation planning. The method used is the method of description and observation. From the calculation results, the optimal foundation is obtained using a diameter of $40 \mathrm{~cm}$ with screw reinforcement D16 distance 125 with the content of 5 reinforcement. When calculating piles, it is better to use pile group control and lateral force control so that the planned foundation construction is able to support the planned load.
\end{abstract}

Keywords: Foundation, Pillar Foundation, Construction, Soil

\begin{abstract}
Abstrak
Pondasi merupakan suatu konstruksi pada bagian dasar bangunan yang berfungsi meneruskan beban dari bagian atas struktur bangunan ke lapisan tanah yang berada di bagian bawahnya Pondasi jenis tiang merupakan pondasi yang sering kali direncakan pada kondisi yang demikian, maka dari itu perlu perhitungan yang tidak tepat pada perencanaan pondasi, metode yang digunakan ialah metode penjabaran dan pengamatan. Dari hasil perhitungan, didapat pondasi yang optimal mengunakan diameter $40 \mathrm{~cm}$ dengan tulangan besi ulir D16 jarak 125 dengan isi 5 tulangan. Jika menghitung tiang pancang lebih baik menggunakan kontrol kelompok tiang serta kontrol gaya lateral agar konstruksi pondasi yang direncanakan mampu mundukung beban yang yang di rencanakan.
\end{abstract}

Kata Kunci: Pondasi, Pondasi Tiang, Konstruksi, Tanah 


\section{PENDAHULUAN}

Pondasi merupakan suatu konstruksi pada bagian dasar bangunan yang berfungsi meneruskan beban dari bagian atas struktur bangunan ke lapisan tanah yang berada di bagian bawahnya, [1][2][3].

Pembangunan biasanya dilakukan pada lahan baru atau bangunan yang sudah ada di tambah beban lantai baru. Dari pembangunannya sering timbul masalah-masalah yang diakibatkan oleh kondisi tanah. Hal ini disebabkan tanah tempat berdirinya bangunan merupakan daerah tanah yang labil, [2][4]. Pondasi jenis tiang merupakan pondasi yang sering kali direncakan pada kondisi yang demikian, [5][6]. Dalam hal ini penulis mencoba membuat analisa perhitungan.

Terdapat beberapa permasalahan yang terkadang terjadi di lapangan, yaitu sebagai berikut

1. Perhitungan yang tidak tepat pada perencanaan pondasi

2. Kedalaman pondasi tidak pada kondisi tanah keras

3. Pembebanan yang terjadi

Sesuai dengan latar belakang dan identifiksi masalah tersebut diatas, maka dapat diangkat rumusan masalahnya adalah :

1. Bagaimana pembebanan yang terjadi pada Hotel Merdeka Tulungagung ?

2. Bagaimana perhitungan pondasi yang optimal pada Hotel Merdeka Tulungagung ?

3. Bagaimana perhitungan kontrol gaya geser satu arah dan stabilitas pondasi tiang pada Hotel Merdeka Tulungagung?

Untuk menghindari melebarnya permasalahan, penulis membuat batasan - batasan permasalahan :

1. Analisis perhitungan menggunakan manual.

2. Tidak menghitung RAB (Rencana Anggaran Biaya)

\section{METODE PENELITIAN}

\subsection{Tinjauan Umum}

Penyelidikan tanah dasar dalam mendesain bangunan geotektonik sangat penting sebab seorang engineering harus memahami geologi tanah, sifat tanah dan kekuatan tanah setempat. Jenis investigasi disesuaikan dengan jenis proyek, kepentingan proyek, dan kondisi tanah asli dan tes 3 lapangan menjadi sangat penting bila dilakukan pada tanah yang sangat sensitif terhadap gangguan.

\subsection{Pembebanan}


Beban adalah gaya luar yang bekerja pada suatu struktur. Besar beban yang bekerja pada sauatu struktur diatur oleh peraturan pembebanan yang berlaku, [7][8]. Beberapa jenis beban yang sering dijumpai antara lain :

a. Beban Mati

Beban mati adalah berat dari semua bagian suatu gedung yang bersifat tetap selama masa layan struktur. Termasuk unsur-unsur tambahan, finishing, mesin-mesin serta peralatan yang tetap yang merupakan bagian tak terpisah dari gedung tersebut. Yang termasuk beban ini misalnya, berat sendiri struktur, pipa-pipa saluran air maupun listrik, AC, plafond, dan lain sebagainya, [9][10]. b. Beban Hidup

Beban hidup termasuk kedalam beban gravitasi, yaitu jenis beban yang timbul akibat penggunaan suatu gedung selama masa layan gedung tersebut. Beban manusia, peralatan yang dapat dipindahkan, kendaraan bermotor, serta barang/benda lain yang letaknya tidak permanen. Oleh karena besar dan lokasi beban hidup berubah-ubah, maka penentuan beban hidup dengan tepat merupakan suatu hal yang cukup sulit, [11].

\section{c. Beban Gempa}

Beban gempa adalah beban yang bekerja pada suatu struktur akibat dari gerakan tanah yang disebabkan karena adanya gempa bumi (baik gempa tektonik maupun vulkanik) yang mempengaruhi struktur tersebut, [12]. Gempa mengakibatkan beban pada struktur karena interaksi tanah dengan struktur dan karakteristik respon struktur [13].

d. Beban Angin

Beban angin adalah beban yang bekerja pada suatu struktur akibat pengaruh struktur yang memblok aliran angin, sehingga energi kinetik angin akan dikonversikan menjadi tekanan energi potensial yang menyebabkan terjadinya beban angin. Beban angin ditentukan dengan efek beban angin pada suatu struktur bergantung pada berat jenis dan kecepatan udara, sudut luas angin, bentuk dan kekuatan struktur, dan angin faktor lainnya [14].

\subsection{Penyelidikan Tanah}

Salah satu parameter penting dalam proses perencanaan suatu elemen pondasi adalah daya dukung tanah, serta lokasi kedalaman tanah keras. Dengan diketahuinya besar daya dukung tanah, maka dapat dihitung besar kapasitas pondasi yang akan dipilih, [15][16].

\subsection{Pemilihan jenis Pondasi}

Pemilihan jenis pondasi yang tepat harus dipertimbangkan kemudahan dalam melaksanakannya, biaya konstruksi, dan kinerja pondasi tersebut. Suatu pilihan jenis pondasi dapat dikatakan baik apabila dapat dikerjakan dengan mudah dan dengan biaya konstruksi yang minimal, [17][18]. 


\subsection{Menentukan Dimensi Pondasi}

Apabila kedalaman dasar pondasi telah ditentukan, seterusnya ukuran pondasi dihitung untuk memikul beban rencana yang disalurkan oleh struktur bagian atas. Untuk pondasi tiang pancang, perlu diperhitungkan dimensi penampang tiang, panjang tiang, jumlah tiang dalam satu pile cap, serta ukuran dari pile cap itu sendiri yang meliputi panjang, lebar, dan tebal, [17].

\subsection{Pondasi Tiang Pancang}

Fungsi dan kegunaan dari pondasi tiang pancang adalah untuk memindahkan atau mentransfer bebanbeban dari konstruksi di atasnya (super struktur) ke lapisan tanah keras yang letaknya sangat dalam, [19].

Dalam pelaksanaan pemancangan pada umumnya dipancangkan tegak lurus dalam tanah, tetapi ada juga dipancangkan miring (battle pile) untuk dapat menahan gaya-gaya horizontal yang bekerja.

\subsection{Gaya Geser}

Gaya geser negatif (negative skin friction) adalah suatu gaya yang bekerja pada sisi tiang pancang dimana gaya tersebut justru bekerja kearah bawah sehingga memberikan penambahan beban secara vertikal selain beban luar yang bekerja, [20].

\subsection{Daya Dukung}

Pondasi tiang kelompok di gunakan apabila daya dukung ijin tanah pondasi tiang tunggal kurang dari beban maksimum yang di pikul di atasanya. Maka dari itu di butuhkan pondasi tiang kelompok yang di gunakan pada tugas akhir ini berdasarkan tiang tunggal, [21][22].

\subsection{Lokasi Studi}

Studi Perencanaan yang menjurus pada struktur pondasi gedung yang akan digunakan untuk hotel berada di Jl Ir. Soekarno Hatta, Lembu Peteng , Kabupaten Tulungagung, Jawa Timur.

\subsection{Survey Lapangan}

Sebelum melakukan studi perencanaan mengenai struktur pondasi gedung yang akan digunakan terhadap hotel merdeka Tulungagung, terlebih dahulu dilakukan survey lapangan, berikut ini adalah langkah langkah dalam melakukan survey lapangan:

a. Mencari data-data lapangan yang berkaitan dengan daya dukung tanah terhadap pondasi salah satunya adalah data sondir.

b. Menghitung data lapangan (sondir).

c. Penyusan laporan.

\subsection{Metode Pengumpulan Data}


Banyak metode dalam penulisan tugas akhir, dalam hal ini penulis hanya meggunakan dua metode untuk menulis laporan tugas akhir ini, yaitu salah satunya adalah metode pengamatan dan metode penjabaran.

\section{HASIL DAN PEMBAHASAN}

\subsection{Pembebanan}

Perhitungan Beban Atap

Atap : 14,00x8,50x 100,00

$=14.565,00$

Beban Mati Lantai 4

$\begin{array}{lll}\text { Plat Beton } & : 9,0 \times 6,5 \times 0,12 \times 2400 & =16.483,50 \\ \text { Balok } & : 32,00 \times 0,30 \times 0,50 \times 2400 & =11.520,00 \\ \text { Kolom } & : 0,40 \times 0,50 \times 5,0 \times 2400 & =2.400,00 \\ \text { Plafond } & : 9,00 \times 6,50 \times 18,00 & =1.053,00 \\ \text { Keramik } & : 9,00 \times 6,50 \times 24,00 & =1.404,00 \\ \text { Dinding } & : 22,00 \times 5,00 \times 250,00 & =27.500,00 \\ \text { Total } & & =60.360,50\end{array}$

Beban Mati Lantai 3

\begin{tabular}{|c|c|c|}
\hline Plat Beton & $: 9,0 \times 6,5 \times 0,12 \times 2400$ & $=16.483,50$ \\
\hline Balok & $: 32,00 \times 0,30 \times 0,50 \times 2400$ & $=11.520,00$ \\
\hline Kolom & $: 0,40 \times 0,50 \times 5,0 \times 2400$ & $=2.400,00$ \\
\hline Plafond & $: 9,00 \times 6,50 \times 18,00$ & $=1.053,00$ \\
\hline Keramik & $: 9,00 \times 6,50 \times 24,00$ & $=1.404,00$ \\
\hline Dinding & $: 30,00 \times 5,00 \times 250,00$ & $=37.500,00$ \\
\hline Total & & $=70.298,50$ \\
\hline \multicolumn{3}{|c|}{ Beban Mati Lantai 2} \\
\hline Plat Beton & $: 9,0 \times 6,5 \times 0,12 \times 2400$ & $=16.483,50$ \\
\hline Balok & $: 32,00 \times 0,30 \times 0,50 \times 2400$ & $=11.520,00$ \\
\hline Kolom & $: 0,40 \times 0,50 \times 5,0 \times 2400$ & $=2.400,00$ \\
\hline Plafond & $: 9,00 \times 6,50 \times 18,00$ & $=1.053,00$ \\
\hline Keramik & $: 9,00 \times 6,50 \times 24,00$ & $=1.404,00$ \\
\hline Dinding & $: 30,00 \times 5,00 \times 250,00$ & $=37.500,00$ \\
\hline Total & & $=70.298,50$ \\
\hline \multicolumn{3}{|c|}{ Beban Mati Lantai 1} \\
\hline Plat Beton & $: 9,0 \times 6,5 \times 0,12 \times 2400$ & $=16.483,50$ \\
\hline
\end{tabular}




$\begin{array}{lll}\text { Balok } & : 32,00 \times 0,30 \times 0,50 \times 2400 & =11.520,00 \\ \text { Kolom } & : 0,40 \times 0,50 \times 5,0 \times 2400 & =2.400,00 \\ \text { Plafond } & : 9,00 \times 6,50 \times 18,00 & =1.053,00 \\ \text { Keramik } & : 9,00 \times 6,50 \times 24,00 & =1.404,00 \\ \text { Dinding } & : 26,00 \times 5,00 \times 250,00 & =32.500,00 \\ \text { Total } & & =65.290,50 \\ \text { Beban Hidup } & : 9,00 \times 6,50 \times 250,00 & =14.625,00 \\ \text { Atap } & : 9,00 \times 6,50 \times 250,00 & =14.625,00 \\ \text { Lantai } 4 & : 9,00 \times 6,50 \times 250,00 & =14.625,00 \\ \text { Lantai 3 } & : 9,00 \times 6,50 \times 250,00 & =14.625,00 \\ \text { Lantai } 2 & : 9,00 \times 6,50 \times 250,00 & =14.625,00 \\ \text { Lantai } 1 & & \\ \text { Jumlah Beban Total } & \end{array}$

\subsection{Perhitungan Pondasi yang Optimal}

Metode mayerhoff (1956)

$$
\begin{aligned}
q c_{r}= & \frac{40+45+45+45+65+70+85+85}{8} \\
= & 60 \mathrm{~kg} / \mathrm{cm}^{3} \\
\text { Qult } & =60 \times(3,14 \times 20 \times 20)+758 \times(3,14 \times 40) \\
& =170.564,8 \mathrm{~kg} \\
\text { Qall } & =\frac{\text { Qult }}{F K} \\
\text { Qall } & =\frac{170.564}{2,5} \\
& =68.225,9 \mathrm{~kg} \\
& =68,23 \text { ton }
\end{aligned}
$$

\subsection{Kontrol Gaya Geser dan Stabilitas Pondasi}

a. Gaya Geser

$\varphi \vee c=\varphi \frac{1}{6} \sqrt{ } f c^{\prime} b d$

$\varphi \vee c=5 \frac{1}{6} \sqrt{ } 24,9 \times 5800 \times 450$ 
$\varphi \vee c=10.853 .250 \mathrm{~N}$

$\varphi \vee c=1.085,33$ ton

$\varphi \mathrm{Vc}=1.085,33$ ton $>\mathrm{Vu}=348,04$ ton

(OKE)

Mencari penampang kritis (B')

$\left(B^{\prime}\right)=$ Lebar Kolom $+2\left(\frac{1}{2}\right) d$

$\left(\mathrm{B}^{\prime}\right)=40+2\left(\frac{1}{2}\right) 45$

$\left(\mathrm{B}^{\prime}\right)=85 \mathrm{~cm}$

$\mathrm{Vu}=\sigma\left(\mathrm{L}^{2}-\mathrm{B}^{\prime 2}\right)$

$\mathrm{Vu}=26,67\left(5,8^{2}-\mathrm{B}^{\prime 2}\right)$

$\mathrm{Vu}=877,91$ ton

b. Stabilitas Pondasi

Cek Guling

$\mathrm{n}=\mathrm{MP} / \mathrm{MG} 10,506 \mathrm{t} / \mathrm{m} 2 ~ \gg>1,5 \mathrm{t} / \mathrm{m} 2$ maka AMAN

Cek Geser

$\mathrm{n}=\Sigma \mathrm{W} / \Sigma \mathrm{E} 5,977 \mathrm{t} / \mathrm{m} 2 \gg>1,5 \mathrm{t} / \mathrm{m} 2$ maka AMAN

Penurunan Kekuatan Tumit

Terhadap Geser

$0,0454 \mathrm{t} / \mathrm{m} 2 ~ \gg>15 \mathrm{t} / \mathrm{m} 2$ maka AMAN

Terhadap Tarik

$0,0596 \mathrm{t} / \mathrm{m} 2$ 〉> $30 \mathrm{t} / \mathrm{m} 2$ maka AMAN

Penurunan Kekuatan Kaki

Terhadap Geser

$1,5078 \mathrm{t} / \mathrm{m} 2 ~ \gg>15 \mathrm{t} / \mathrm{m} 2$ maka AMAN

Terhadap Tarik

$2,3558 \mathrm{t} / \mathrm{m} 2$ 〉> $30 \mathrm{t} / \mathrm{m} 2$ maka AMAN

Penurunan Kekuatan Badan

$\sigma \cdot \max 2,98666 \mathrm{t} / \mathrm{m} 2 ~ \gg>150 \mathrm{t} / \mathrm{m} 2$ maka AMAN

$\sigma \cdot \min 2,76787 \mathrm{t} / \mathrm{m} 2 \gg>300 \mathrm{t} / \mathrm{m} 2 \mathrm{maka}$ AMAN

\section{KESIMPULAN}

Berdasarkan hasil perhitungan pondasi tiang di Hotel Merdeka Tulungagung dapat beberapa kesimpulan, yakni sebagai berikut : 
1. Dari hasil analisis pembebanan yang terjadi pada Hotel Merdeka Tulungagung bisa kita simpulkan bahwa :

B. Hidup dan B. Mati $=353.938 \mathrm{~kg}$

Beban Gempa $=21.165,5 \mathrm{~kg}$

Beban Angin $=4.095 \mathrm{~kg}$ Total $=379.198,5 \mathrm{~kg}$

2. Dari hasil perhitungan, didapat pondasi yang optimal mengunakan diameter $40 \mathrm{~cm}$ dengan tulangan besi ulir D16 jarak 125 dengan isi 5 tulangan, dan dikatakan AMAN

3. a).Perhitungan Kontrol Gaya Geser Satu Arah $=1.085,33$ ton $>$ Gaya Geser Nominal $=$ 348,04 ton dikatakan AMAN

Perhitungan Kontrol Gaya Geser Dua Arah $=1.272,45$ ton $>$ Gaya Geser Nominal $=877,91$ ton dikatakan AMAN

b) Stabilitas kontrol pondasi

Terhadap guling

$8,433 \mathrm{t} / \mathrm{m} 2>1,5 \mathrm{t} / \mathrm{m} 2$-> Aman

Terhadap geser $6,057 \mathrm{t} / \mathrm{m} 2>1,5 \mathrm{t} / \mathrm{m} 2$-> Aman

Penurunan Kekuatan tumit

Terhadap geser

$0,1003 \mathrm{t} / \mathrm{m} 2<15 \mathrm{t} / \mathrm{m} 2 \rightarrow$ Aman

Terhadap tarik

$0,0348 \mathrm{t} / \mathrm{m} 2<30 \mathrm{t} / \mathrm{m} 2 \rightarrow$ Aman

Kekuatan Kaki

Terhadap geser

$0,5847 \mathrm{t} / \mathrm{m} 2<15 \mathrm{t} / \mathrm{m} 2->$ Aman

Terhadap tarik

$0,1958 \mathrm{t} / \mathrm{m} 2<30 \mathrm{t} / \mathrm{m} 2 \rightarrow$ Aman

Kekuatan Badan

$\sigma \cdot \max$

$2,7481 \mathrm{t} / \mathrm{m} 2<150 \mathrm{t} / \mathrm{m} 2->$ Aman

$\sigma . \min$

$2,9210 \mathrm{t} / \mathrm{m} 2<300 \mathrm{t} / \mathrm{m} 2->$ Aman 


\section{SARAN}

Dari hasil perhitungan perencanaan pondasi tiang pancang pada Hotel MerdekaTulungagung diatas penulis memberikan saran sebagai berikut :

1. Supaya lebih mudah proses menghitung diperlukan persiapan dengan memperoleh data teknis yang lengkap, dimana data tersebut nantinya akan sangat menunjang dalam membuat rencana analisa perhitungan, sesuai dengan standar dan syarat-syaratnya.

2. Agar mudah,cepat dan hasil yang akurat proses menghitung baiknya menggunakan aplikasi Microsoft Excel.

3. Jika menghitung tiang pancang lebih baik menggunakan kontrol kelompok tiang serta kontrol gaya lateral agar konstruksi pondasi yang direncanakan mampu mundukung beban yang yang di rencanakan.

\section{UCAPAN TERIMAKASIH}

Dalam penyusunan artikel ini, penulis ucapkan terimakasih kepada dosen pembimbing dan Universitas Kadiri. Penulis berharap agar artikel ini dapat bermanfaat bagi pembaca.

\section{DAFTAR PUSTAKA}

[1] J. Hadihardaja, "Rekayasa Pondasi I Konstruksi Penahan Tanah.” 1997.

[2] A. I. Candra, "ANALISIS DAYA DUKUNG PONDASI STRAUSS PILE PADA PEMBANGUNAN GEDUNG MINI HOSPITAL UNIVERSITAS KADIRI,” Ukarst, vol. 1, no. 1, pp. 63-70, 2017.

[3] A. I. Candra, A. Yusuf, and A. R. F, "Studi Analisis Daya Dukung Pondasi Tiang Pada Pembangunan Gedung Lp3M Universitas Kadiri," J. CIVILA, vol. 3, no. 2, p. 166, 2018, doi: $10.30736 /$ cvl.v3i2.259.

[4] E. Fajarsari and S. Wulandari, "Perencanaan Pondasi Tiang Bor Pada Proyek Cikini Gold Center," Pros. PESAT, vol. 5, no. 0, pp. 49-56, 2013.

[5] Z. Arifin, "Komparasi Daya Dukung Aksial Tiang Tunggal Dihitung Dengan Beberapa Metode Analisis Tesis,"pp. 1-126, 2007, doi: 10.2174/156720105774370221.

[6] T. W. Kuningsih, A. P. Putri, X. Meiprastyo, and L. Belakang, "AKTUALISASI KAPASITAS DAYA DUKUNG AKSIAL PONDASI TIANG PANCANG BERDASARKAN PARAMETER TANAH DAN STATIC LOADING TEST KASUS: PERENCANAAN GEDUNG DEWI SARTIKA DI UNJ,” J. Kaji. Tek. Sipil, vol. 3, no. 1, pp. 22-31, 2018.

[7] D. Hartanto, Y. Cahyo, S. Winarto, and A. I. Candra, "PERENCANAAN PONDASI TIANG PANCANG PADA GEDUNG SEKRETARIAT DEWAN DPRD KABUPATEN 
KEDIRI,”Jurmateks, vol. 1, no. 2, pp. 303-312, 2018.

[8] S. Balamba, “Analisis Respons Dinamik Pondasi Tiang Pancang," J. Ilm. Media Eng., vol. 3, no. 3, pp. 204-213, 2013.

[9] Badan Standardisasi Nasional Indonesia, "SNI 2847 : 2013 Persyaratan Beton Struktural untuk Bangunan Gedung," pp. 1-265, 2013.

[10] J. C. McCormac, “Desain Beton Bertulang Jilid 1,” Sipil; Pembangunan. p. 2006, 2006.

[11] B. Direktorat Penyelidikan Masalah Bangunan, "Peraturan-Pembebanan-Indonesia1983." pp. 3-32, 1981.

[12] K. C. A. Indarto H., Andiyarto, H.T.C., Putra, “"Aplikasi SNI Gempa 1726:2012 for Dummies'.," Univ. Negeri Semarang, 2013.

[13] L. Sintyawati, S. Winarto, A. Ridwan, and A. I. Candra, "STUDI PERENCANAAN STRUKTUR PONDASI TIANG PANCANG GEDUNG FAKULTAS SYARIAH IAIN PONOROGO,” Jurmateks, vol. 1, no. 2, pp. 227-237, 2018.

[14] F. Febriantoro, Y. C. S. P, and A. R. A, "STUDY PERENCANAAN PONDASI TIANG PANCANG JEMBATAN SEMBAYAT BARU II KECAMATAN MANYAR, KABUPATEN GRESIK,” Jurmateks, vol. 1, no. 1, pp. 148-159, 2018.

[15] E. Pamungkas, A., Harianti, "Desain Pondasi Tahan Gempa," Desain Pondasi, 2013.

[16] T. Y. Purnomo, L. D. Krisnawati, and Y. C. Sp, "KAJIAN JEMBATAN KECAMATAN SENDANG (RUAS JALAN TUGU - PABYONGAN) KABUPATEN TULUNGAGUNG DENGAN METODE KOMPOSIT, ”Jurmateks, vol. 1, no. 1, pp. 112 $125,2018$.

[17] A. Setiawan, "Perancangan Struktur Beton Bertulang Berdasarkan SNI 2847 : 2013," pp. $1-2,2016$.

[18] I. . Luthfiani, F.L., Nurhuda, I., \& Atmanto, “Analisis Penurunan Bangunan Pondasi Tiang Pancang dan Rakit Pada Proyek Pembangunan Apartemen Surabaya Central Business District,” J. Karya Tek. Sipil, vol. 6, no. 1976, pp. 166-179, 2017.

[19] M. Periyadi, "Perencanaan Type Pondasi Tiang Pancang 'Hotel Rich Palace' Surabaya dengan Zona Gempa Kuat,” 2012.

[20] J. Hadihardaja, "Rekayasa Pondasi II - Pondasi Dangkal dan Pondasi Dalam." .

[21] R. Gunawan, "Pengantar Teknik Fondasi," p. 93, 1393.

[22] Joseph E. Bowles, “Analisa dan Desain Pondasi Jilid 1,” no. 9, pp. 1689-1699, 2013. 